\title{
A psiquiatria na época de Freud: evolução do conceito de psicose em psiquiatria*
}

Para apresentar a psiquiatria da época de Freud, inicio pela palavra psicose. A palavra psicose foi grafada pela primeira vez em 1845, por um psicólogo alemão, Feuchtersleben, e apareceu no ano seguinte, pela primeira vez, no Zeitschrifte fur Psychiatrie und Gerichtliche Medizin (Jornal de Psiquiatria e Medicina Forense).

Segundo o Petit Robert, a palavra psicose só foi usada na França em 1869, e, se acompanharmos toda a literatura do século XIX, veremos que o primeiro aparecimento da palavra psicose, com grande destaque, é no trabalho de Möbius, de 1892, quando ele divide as doenças mentais em psicoses exógenas e endógenas. Então, psicose é uma palavra de curso muito restrito, especialmente no século XIX. Quando Kraepelin faz a sua sistemática, a palavra psicose não aparece. Depois ela vai surgir freqüentemente em todos os tratadistas, como veremos.

O livro de Pinel, Traité sur la manie, pode ser considerado a publicação número um da psiquiatria. Nesse trabalho, todas as coisas que têm relação com a loucura são chamadas de mania. A melancolia é uma mania de um objeto único, mostrando que ele percebeu a monoideação do melancólico, mas exagerou. Já quando escreve o seu segundo livro, oito anos após - o Traité médico-philosophique de l'aliénation mental -, já abandona aquele conceito global de que mania era a loucura e começa a pensar na classificação e na ordenação das loucuras, que vêm a ser feitas em 1838, pelo seu discípulo Esquirol, no Traité des maladies mentales. Mas, continua ainda a idéia fundamental da loucura, a loucura como uma manifestação global e muito especial, que tem uma relação certamente com o sistema nervoso.

E é o primeiro dos grandes psiquiatras alemães, Griensinger, quem formula a célebre expressão: "doenças mentais são doenças cerebrais". E Griensinger deixa também um outro caminho, que em psicanálise será seguido, que a desordem mental, a perturbação mental, a doença mental são uma coisa única. Não existem variedades, nem modalidades. Ela segue um ciclo, é um fenômeno evolutivo que começa com a mania, passa pela melancolia, segue-se no delírio e termina por uma diminuição global das funções mentais, que é a demência. Isto ficou estabelecido; a noção de alienação persistiu. Quando Morel escreve o seu Traité des maladies_mentales, faz uma dedicatória extremamente engraçada, porque dedica o livro a Gilles Falret, "mon premier maître en aliénation mental".

Em seguida, os grandes clínicos vão descrevendo variedades de loucuras, como Falret, que descreveu la folie circulaire - a loucura circular-, depois Baillarger, que descreveu la folie de double forme - a loucura de dupla forma -, e, mais tarde, Magnan, com o delírio alucinatório crônico progressivo. Não há a palavra psicose. A loucura apresenta-se sob essas formas, sob essas variedades.

Há um progresso bastante grande na ordenação dos conhecimentos psiquiátricos com o trabalho de Kahlbaum, em 1870. Kahlbaum, pela primeira vez, distingue grupos de sintomas, que hoje chamamos síndromas (Zustandbildern) e unidades de doença (Krankheiten Einheiten). E é nessa linha de trabalho que seu discípulo Hecker descreve a hebefrenia. A hebefrenia foi publicada nos Virchow Archiv, uma revista de clínica geral, em 1871, no volume 52, e tivemos o prazer de poder tê-la traduzida em francês, publicada três anos atrás em L'Evolution Psiquiatrique. Eu li o artigo de Hecker e fiquei entusiasmado; é absolutamente moderno; aprende-se; tem muita observação; é de uma densidade clínica muito grande.

Também nessa época, em 1875, é publicado em Viena, na cidade de Freud, o livro de Krafft-Ebing, Psychopatia sexualis, no qual pela primeira vez são cunhados os nomes sadismo e masoquismo.

Em 1896, Kraepelin, que vinha publicando sucessivamente edições do seu já então Manual de psiquiatria (no começo chamava-se compêndio, era um livro pequenininho, fininho e terminou numa grande obra de quatro imensos volumes), prepara a primeira sistematização da psiquiatria, criando as entidades clínicas. E aí, então, chamou atenção o aparecimento de duas formas de entidades clínicas que ele fez, pela fusão da mania, da melancolia, da loucura de dupla forma, da loucura circular, a que deu o nome de manische-depressive Irrsinnloucura maníaco-depressiva. E, ao outro grupo de psicoses delirantes, que tinha aspectos também motores, catatônicos, que começavam mais cedo sob a forma de hebefrenia e, ao contrário da psicose maníaco-depressiva, cujos períodos terminavam numa volta ao normal - entre parêntesis normal -, essa outra doença, que tinha um curso progressivo, grave, ele chamou demência precoce-dementia praecox. Disse em latim aquela palavra que Morel tinha usado em 1856.

Essa era a psiquiatria que havia na última década do século XIX. Era a obra de Kraepelin, de 1896, a quinta edição, e a psiquiatria francesa, que ainda persistia na separação das doenças por nomes especiais. A demência precoce de Kraepelin ainda era chamada confusão mental crônica, nome que Teixeira Brandão defendia contra a escola de Juliano Moreira, do outro lado daquela vasta chácara da Praia Vermelha.

No entanto, havia sempre a idéia de que a loucura, a doença 
mental, tinha uma base orgânica, e algumas pessoas diziam que a psicose, isto é, a loucura, era a expressão de uma alteração do sistema nervoso, que seria a neurose.

A palavra neurose é muito mais antiga. Ela vem do século XVIII, foi cunhada por Cullen, um médico inglês, e designava afecções (nervosas). Mais tarde ela mudou de aspecto.

É preciso chamar atenção que, também neste final de século, instala-se em Paris a escola de Charcot, que trabalhou enormemente com certos aspectos da doença mental, especialmente com a histeria, com a grande histeria. Quando Charcot obteve o seu Serviço na Salpetrière, ficou localizado ao lado da enfermaria das mulheres epilépticas, e é por isso que se atribui à histeria convulsiva aquele modelo que eles tinham ali ao lado, na outra enfermaria.

Charcot interessou-se por hipnotismo; ele mostrou que as manifestações psíquicas podiam se transformar em sintomas corporais. Ele cultivou essa histeria, que podemos conhecer hoje com muita perfeição, porque havia no seu serviço um homem chamado Berger, que era um excelente desenhista e desenhou todas as fases da histeria, como se pode ver não só no livro de Berger, como algumas dessas gravuras estão reproduzidas no livro famoso de Gilles de la Tourette, de 1881, sobre a histeria, que ele chama hystérie normale (nós hoje ficamos um pouco espantados, mas era o tipo, hystérie normale). E, também, pelo excelente documentário fotográfico. A fotografia já nascia, e a Clínica da Salpetrière publicou esses retratos. Eu uma vez fiz uma grande conferência em Madri e projetei um desenho de Berger e um retrato da nova iconografia da Salpetrière, que nós temos completa aqui na biblioteca do Instituto de Neurologia, na Venceslau Brás. Então, pude mostrar que realmente as histéricas de Charcot chamavam atenção. Algumas dessas fotografias parecem estilos de estrelas de Hollywood dos anos 20, dos anos 30, aquelas atitudes passionais, aquelas variações. Estão todas muito bem localizadas.

Isto deu a Charcot um nome enorme e fez com que um jovem médico vienense quisesse passar lá algum tempo. Eu não sei, mas a minha impressão é que, da França, Freud trouxe mais uma certa atitude em favor do hipnotismo, do que propriamente a doutrina das neuroses defendida por Charcot, que ele depois mudará bastante.

Então, na época de Freud, as doenças mentais não tinham ainda o nome psicose. Esse nome já tinha sido criado, mais se tornou mais comum nos tratados. Por exemplo, o tratado de Aschaffenburg, que é de 1911, já usa psicoses sintomáticas; no tratado de Bumke, já do fim da década de 20, a loucura maníacodepressiva transforma-se em psicoses afetivas.

Mas, o conhecimento da doença mental vem a se fazer posteriormente. Há aqui então, duas linhas muito importantes, que marcam o pensamento da especialidade: a linha da psiquiatria e a linha da psicanálise. Freud começa com seus trabalhos, uma nova orientação, uma nova visão, novos dados, e a psiquiatria começa a receber o influxo de ciências psicológicas.
O autor que terá importância na formação do pensamento de Karl Jaspers, que passou como um meteoro, iluminando toda a psiquiatria, foi Dilthey, especialmente distinguindo as duas maneiras de interpretar os fenômenos psicopatológicos: a compreensão e o esclarecimento* - Verständnis e Erklärung. Verstandnis, a compreensão, é um dado psicológico, é o que fazem todos os psicólogos, os psicanalistas, que procuram compreender as manifestações clínicas.

Esclarecer é explicar o fenômeno pela sua causa, pela sua origem, é descobrir a lesão cerebral. Quando Kreutzfeld \& Jaccobi encontram alterações nos núcleos de base correspondentes a uma determinada psicose, quando os estudos de todos os grandes mestres da anatomia patológica terminam no achado de Nogucchi \& Moro da espiroqueta na córtex, e se conhece a natureza da paralisia geral, nós estamos esclarecendo, estamos explicando pela causa. O que marcava a psiquiatria de Kraepelin é que ele, tendo vindo da medicina, sempre esperava uma explicação causal.

(Aqui há um pequeno trecho perdido, pois um pedaço da conferência não foi gravado no momento de mudança de lado da fita).

(...) Kraepelin teve a fantasia de pensar que cada doença mental tinha sua etiologia própria. Evidentemente que, quando nós encontramos uma psicose como a psicose da pelagra, com todas as características como foi descrita por Llopis, pensamos que esse ideal não era assim tão abstruso. Quando ele pôde mostrar que as alucinações cutâneas dos cocainômanos eram devidas à presença de pequenos cristais de cocaína sob a pele, havia uma explicação causal e etiológica. Mas isto caiu muito cedo. Ainda não havia sido publicado o grande monumento de Kraepelin, que é a $8^{a}$ edição do seu tratado, que foi editado em quatro volumes pela Casa Barth (começou em 1904 e acabou em 1913), quando começavam Hoche e outros a dizer que a manifestação da doença mental não era por doenças, mas por síndromas.

E é sobretudo o trabalho de Bonhoeffer, que está publicado no grande tratado de psiquiatria de Aschaffenburg, sobre as psicoses sintomáticas, que mostrou que todas as causas externas produzem o mesmo quadro mental. Esse quadro tem um sintoma central: o sintoma obrigatório. É a primeira vez que aparece a idéia de um sintoma obrigatório na doença mental, que é a turvação da consciência.

A turvação da consciência, a mudança da consciência, aparece nesse trabalho como a coisa fundamental. Isso foi caracterizado especialmente mais tarde por dois psiquiatras alemães, Stertz \& Ewald, e foi visto que traumatismos, infecções, tóxicos exógenos, desordens metabólicas, todos esses elementos produzem o mesmo quadro mental, a psicose sintomática, e que, ao contrário, um agente único, o etanol, provoca embriaguez agu$\mathrm{da}$, delirium tremens, alucinose dos bebedores, epilepsia e demência. Então, nós vamos ver que a etiologia não serve.

Kraepelin acentuou em seguida a evolução. Ele tinha feito a grande separação das psicoses chamadas endógenas em

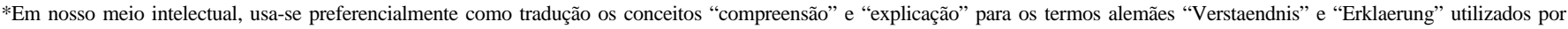
Dilthey (nota do editor). 
maníaco-depressivas, cujas crises tinham de ter um fim bom, um restitutio ad integra até certo ponto, e a demência precoce, que já se chamava então esquizofrenia (depois dos trabalhos de Bleuler), que tinha um curso crônico. Na obra inicial de Bleuler, Dementia Praecox de 1911, não existe a palavra incurabilidade. Finalmente, a terminação e o quadro anatomopatológico. Esse conjunto de elementos: síndrome, fator etiológico, decurso, terminação e quadro anatomopatológico, só foi preenchido em toda a psiquiatria pela paralisia geral. É um modelo inatingível e que não importa, porque inclusive acabou. Era tão bom que acabou. Ficou então a doença mental, a psicose, para ser estudada mais profundamente.

A partir do mecanismo da compreensão, Jaspers publica, em 1910, um trabalho sobre o desenvolvimento ou processo, em que ele estuda os delírios de ciúme. Em 1913, ele lança a sua grande Psicopatologia Geral. A Psicopatologia Geral representa na história da psiquiatria o que é $O$ Cravo Bem Temperado para o piano, tenho dito várias vezes. Quem não leu a Psicopatologia Geral de Jaspers não pode seguir cursos adiantados em psiquiatria. É fundamental. Nesse livro, Jaspers mostra que a doença mental tem uma estrutura. Essa estrutura caracteriza-se por uma perda do relacionamento com o mundo, com o eu e a instituição de uma série de sintomas secundários, delírios, alucinações, que trazem cada vez mais uma mudança que caracteriza a verdadeira loucura, o delírio.

A obra de Jaspers foi revista por ele em 1942.* Jaspers tinha sofrido muito, tinha passado fechado, isolado, todo o tempo da guerra. (Após a segunda guerra) ele tinha sido chamado (de volta à universidade) e feito reitor em Heidelberg.** (Jaspers) teve a triste idéia de publicar um livro denominado Die Schuldfrage (O problema da culpa), em que assume a culpa do povo alemão pelo nazismo e pelas atrocidades, sobretudo contra os judeus, de uma maneira completa. A casa dele foi apedrejada no dia seguinte, e ele teve de se exilar na Basiléia.*** De modo que a revisão de sua obra psiquiátrica, feita nas edições sucessivas, nessas que correm hoje aqui, não é completa, porque ele não deu valor ao homem que continuou a sua obra, que foi Kurt Schneider.

Kurt Schneider, em 1945, publicou uma psicopatologia em que dava uma nova ordenação à psiquiatria. De um lado, as psicoses de base cerebral; elas podem ser agudas ou podem ser crônicas; caracterizam-se pela existência de um quadro anatomopatológico, têm uma causa, têm uma evolução muito típica. E há, do lado oposto, todas as reações vivenciais anormais e as manifestações de personalidade. E, no meio dessas duas, existem as duas psicoses que parecem ser cerebrais, mas para as quais nós não temos prova nenhuma: a psicose maníaco-depressiva e a esquizofrenia. O conceito de endogeneidade que foi depois trabalhado por Weitbrecht, que tem sido muito discutido e foi trabalhado também por Tellenbach, não chega a explicar. Nesse momento, há um grupo de pesquisadores que concentram seus trabalhos na Universidade de Toronto. Eles recebem material de esquizofrênicos mortos em nove hospitais psiquiátricos famosos. Eles estão contando receptores de células, para ver se descobrem alguma coisa que seja típica da anatomia patológica da esquizofrenia. Se isso vai dar certo, não sei.

O que é uma psicose? É difícil dizer e fazer uma definição. Pensando para conversar com vocês esta noite, eu tive a idéia de que a psicose é um espectro que tem dois pólos: o pólo da despersonalização e o pólo da desrealização. Toda psicose é formada por um conjunto de alterações do conhecimento do indivíduo do próprio eu e do conhecimento do indivíduo do mundo em que ele se encontra. Psicose é a alteração entre o eu e o mundo exterior, e a neurose é a alteração da relação entre o ego, o id e o superego. Não sei se ainda se aceita isso, ou se vocês evoluíram mais.

Mas, realmente, na psicose temos de ter esses dois componentes fundamentais: a perda do próprio eu, o eu que se transforma, o eu que se modifica, que chega até à demência, o apagamento total e da relação com o mundo exterior; o eu que se torna agressivo, que se torna diferente, que se torna ameaçador, que se torna perseguidor, que se torna apagado, triste, melancólico, ou que se torna um carnaval de mania. Na realidade, se nós quisermos dizer que a psicose é caracterizada por um sinal, nós não o encontramos.

Apenas as psicoses sintomáticas exógenas têm um sinal central, que é a turvação da consciência. Fora disso, a psicose é formada por elementos os mais diversos da biografia, das experiências, das circunstâncias. É realmente um nome para aquele mais velho fenômeno de todos, a loucura. A loucura descrita pelos trágicos gregos, a loucura descrita na Bíblia é a mesma loucura de hoje, do homem que mora em apartamento em qualquer cidade do mundo. Psicose igual a loucura. Muito obrigado.

(Após a conferência, José Leme Lopes respondeu a perguntas variadas).

\section{Sobre herança e esquizofrenia}

Bem, esse problema é uma das questões centrais da psiquiatria. Ele foi equacionado, até certo ponto, pelos trabalhos dina-

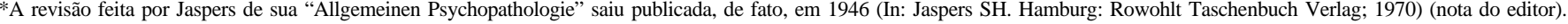

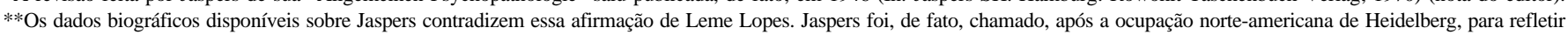

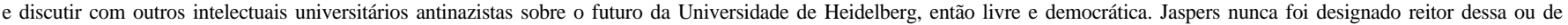
qualquer outra universidade (nota do editor).

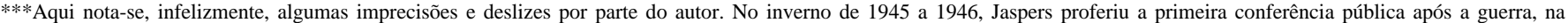

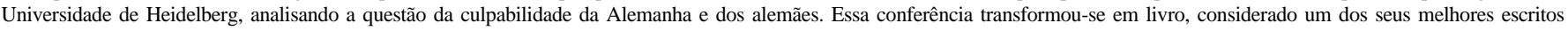

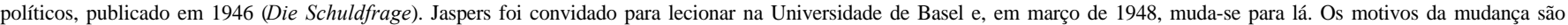

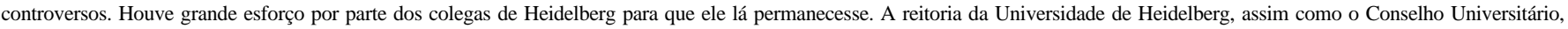

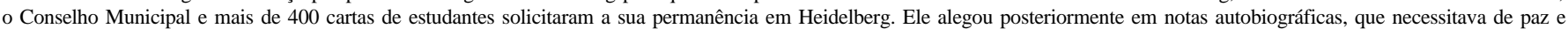

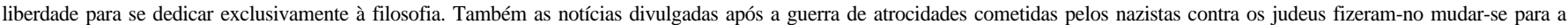

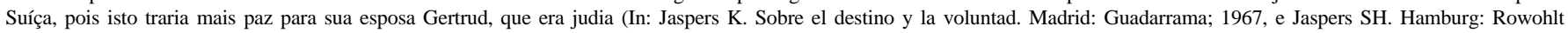
Taschenbuch Verlag; 1970. (nota do editor).
} 
marqueses. A Dinamarca é um país que tem toda a sua população recenseada. Na Dinamarca, estudou-se o problema da adoção, sobretudo da adoção de filhos de esquizofrênicos. Verificou-se que, se um filho de esquizofrênico era colocado em uma família normal, ou se era colocado numa família em que havia esquizofrenia, ele podia se tornar um esquizofrênico de qualquer maneira. Parecia haver um fator hereditário. Esses estudos foram reproduzidos no Canadá, foram reproduzidos em outros lugares, estão em caminho. Sabe-se que para haver esquizofrenia é talvez necessário um ingrediente, um elemento genético. Mas, afirmar, não se pode fazer, pelo menos até o ponto em que eu estudei.

\section{Sobre fatores ambientais e esquizofrenia}

Bem, o homem vive no mundo e vive com o mundo e vive para o mundo. Então, para que ele sofra uma transformação tão grande como é a doença mental, é necessário que no mundo, do mundo e pelo mundo venha a haver influências sobre ele. O peso desses fatores, a mania de quantificar, parece-me que, em psicologia, é muito difícil. Embora hoje toda a psiquiatria que se diz de classe é assim.

Um trabalho só é bem recebido quando tem curvas, quando tem tabelas, quando tem tratamento estatístico. Mas eu penso que é muito difícil ainda nós podermos avaliar. $\mathrm{Na}$ classificação DSM-3, o quarto eixo é o do estresse social. Eu acho aquilo fantasioso, não sei como é que se pode medir aqueles fatores que estão ali e é um dos pontos de grande discussão.

Agora, os fatores ambientais têm alguma influência, sim. Mas nós já saímos daquela fase das mães esquizofrenogênicas e de outras barbaridades que se diz por aí. Porque, na realidade, não sabemos realmente quais são os fatores que são diretamente envolvidos na gênese da esquizofrenia. É possível que seja uma constelação de fatores.

Certamente o ambiente é muito importante. Há algumas pessoas que sofreram quase que um processo de esquizofrenização; de tal modo elas perderam os laços, elas foram rejeitadas, elas foram criadas num clima de hostilidade, que terminaram, evidentemente, voltando-se para dentro de si e criando seu mundo, entrando em autismo.

\section{Sobre a possibilidade das psicoses serem analisáveis}

Uma das coisas que deixei entrever no meu livro Delírio é que aquilo que Jaspers chamava die läzte Sache, a coisa última, aquele muro, no qual o psiquiatra esbarra e não consegue entender a psicose e a loucura, para mim hoje nós temos que por nitrogliglerina, temos de botar um britador, temos de botar uma escada e pular por cima do muro, é isso que me parece que a psicanálise trouxe de bom, e que Jaspers não viu. É que nós vamos poder estabelecer uma nova forma de compreensão, que não é a compreensão fenomenológica jaspersiana, mas que é uma compreensão psicanalítica freudiana, e que essa, talvez, possa furar a psicose. Eu acho que a psicose deve ser tratada e, se ela não é curada, que isso é outra coisa, ela é, pelo menos, adaptada.

\section{Se a palavra psicose significa o mesmo que esquizofrenia}

Para Kurt Schneider, a única psicose propriamente dita é a esquizofrênica. Nas classificações modernas, a psicose maníaco-depressiva está sendo retirada das manifestações psicóticas para entrar do lado das doenças corporais do pânico, e sobretudo ela está sendo considerada uma doença do humor - em inglês mood. Então, psicose propriamente dita fica sendo a esquizofrenia.

\section{Sobre a possibilidade da mãe provocar esquizofrenia no filho}

Se os psicanalistas têm evidências que as mães são esquizofrenizantes, eu tenho bastante dúvidas, porque eu tenho idéia de que a relação mãe e feto, mãe e filho, mãe-infante é de tal modo complexa e profunda que essa manifestação não pode se transformar em uma doença, não pode transformar o elemento simbiótico quase, da mãe e do filho pequeno, em um agente mórbido. Eu até hoje não obtive evidências disso. Há alguns anos assinei aquele Journal of Orthopsychiatry, em que saíram dezenas de artigos sobre mães esquizofrenizantes, e nunca fiquei muito convencido disso. Começa que as observações são muito curtas, muito pequenas, e eu sou a favor de que só podemos conhecer bem um caso quando a observação é muito grande. Foi um dos legados de Jaspers. As observações pequenas não ilustram grande coisa.

\section{Sobre a relação entre genialidade e loucura}

Sobre esse assunto eu tenho pensado muitas vezes. O problema é que o homem tem limites e tem limites para cima. Os limites para cima são a santidade, a genialidade e a loucura. Então, quando nós encontramos um artista com perturbações psíquicas, essas coisas se associam, combinam-se, fundem-se, porque não são da vida de cada dia, não são da coisa comum, do ganha-pão, do trabalho de rotina, mas da evasão, da saída para um limite que nós não podemos mais controlar: a possibilidade de um homem surdo escrever os últimos quartetos, como fez Beethoven, a possibilidade de um homem epiléptico com alterações profundas da consciência pintar quadros, como fez Van Gogh, aquelas últimas pinceladas, aquele campo de trigo com os corvos; a possibilidade de um homem como Machado de Assis sair de uma crise, de uma situação de ausência demorada, molesta, e escrever com harmonia e tranqüilidade o Memorial de Aires. Essas coisas todas aparecem, e também nós temos de aceitar que o que temos dentro de nós é muito forte, e que só nesses limites, nessas explosões é que nós ultrapassamos as raias do normal, da média. É por isso que gênio e loucura se encontram com muita frequiência. Eu penso que não é por acaso, é por necessidade quase.

\section{Sobre a retirada da palavra neurose das Classificações das Doenças Mentais}

Se eu quisesse simplificar as coisas, diria: escreva uma carta ao Spitzer, que é o papa da classificação. Mas eu vou dar uma idéia do que eu penso que seja, não sei se é. Se você fizer uma curva das publicações em revistas de psiquiatria de artigos de 
orientação psicanalítica, você verá que essa curva é extremamente descendente em todos os países de língua inglesa. É porque há um número enorme de revistas especializadas em que os melhores artigos disputam lugar e devem estar esperando época para serem publicados. Mas, ao mesmo tempo, com o sucesso da psicofarmacologia, as pessoas que são responsáveis pela administração da loucura, isto é, dos hospitais, dos locais, ficaram com uma idéia de que limpariam esses hospitais, que acabariam com aquilo tudo e de que não precisavam mais de certas coisas demoradas, complicadas, como é um tratamento psicanalítico. Houve então um certo combate à psicanálise. E, como combater a psicanálise? Acabando com o nome neurose. Eu tenho a impressão de que isso é uma tendência antipsicanalítica que existe nessa classificação americana, e que é seguida, infelizmente, pela Organização Mundial da Saúde. Estou convicto de que a neurose existe, neurose de tipo psiconeurose freudiana. Eu vi muitos casos. Transformar a fobia numa manifestação de prolapso de válvula mitral eu acho impossível. É o que eles estão querendo. Eu acho que isso aí indica uma orientação de pensamento muito típica de uma certa facção que combate a psicanálise nos Estados Unidos, porque a psicanálise dominou de tal modo os Estados Unidos nos anos quarenta e cinqüenta, que houve uma reação. É o pêndulo: agora estão contra, já foram a favor; depois, não sabemos o que acontecerá. Mas continuem a usar na sua clínica o conceito de neurose.

Sobre a conclusão nona do seu livro Delírio, que se segue: "Freud, (1938), já falava em uma substância química capaz de modificar a distribuição de energia no aparelho psíquico. Os neurolépticos têm essa ação. A psicoterapia pode também corrigir a situação psicológica, uma vez que o delírio não é um final, uma coisa última, mas, ao contrário, um ensaio de reconstrução (...). $O$ cérebro pode ser influenciado neuroquímica e psicoterapicamente. Isto mostra a natureza da interface neuropsíquica, isto é, a ligação cérebroeu consciente".

O que eu escrevi nesse número nove é uma síntese de um pensamento que é quase um final da elaboração da minha experiência pessoal. Eu vim de uma escola de medicina, que era na época a grande escola de medicina do Brasil, de Miguel Couto. Aprendi neurologia bastante bem, cheguei até a dirigir centro de estudos no Instituto de Neurologia. Eu já não aprendi tão bem química, nem farmacologia, mas acompanhei esses avanços. Então, a minha formação é uma linha na qual a minha psiquiatria é uma especialidade médica. Como psiquiatra, eu tinha de conhecer, evidentemente, toda a evolução das ciências psicológicas, entre as quais está a psicanálise. E, na realidade, eu estou convencido de que o cérebro pode ser atuado por remédios e por palavras. Isto já está no célebre diálogo de Platão, Górgias, em que ele diz: "a alma se cura com ensalmos e fármacos". Ensalmos eram cânticos religiosos. Nós hoje estamos aceitando os cânticos religiosos. Eu ainda há pouco conversava com um amigo meu sobre as chamadas terapêuticas alternativas, entre as quais está a macumba. E era um crime se dizer isso antigamente. Um livro famoso, escrito no Brasil por Leonídio Ribeiro e Murilo de Campos dizia: "A prática do espiritismo é um problema de polícia, é crime contra o código penal". Hoje em dia nós estamos sabendo que não é. Sabemos que muitas coisas influenciam o cérebro, e é isso que eu penso que faz a dificuldade e o interesse enorme da ciência psiquiátrica, porque ela cuida do homem como um cérebro, ela cuida do homem como um ser social, cuida do homem como um ser afetivo, cuida do homem como um ser religioso. De modo que isso aí eu não mudo uma linha.

\section{Sobre a controvérsia: doença mental - síndrome ou doença}

Bem, o problema fundamental é o seguinte. Na ordenação dos fenômenos psicopatológicos, o homem chegou ao estabelecimento pelas formas clássicas de pensar e hoje em dia pela epistemologia, a tentar arrumar. O modelo médico era o modelo de Virchow, a doença com a sua lesão, a célula como base da patologia, que é continuado hoje em dia e que tomou formas muito sofisticadas, especialmente com a imunologia. Eu não acredito que isto vá resolver o problema da psiquiatria. Não é por dosar HLA ou outros elementos que nós vamos chegar a alguma conclusão, nem se foi suprimido o efeito da dexametasona ou não foi suprimido é melancolia ou não é melancolia. Para mim isso não tem interesse. Pode-se pesquisar, pode-se trabalhar, mas isto não vai resolver o problema. Agora, as doenças mentais têm um certo grupo. Nós conhecemos mais ou menos a filiação delas. Vamos tomar a coisa mais comum de toda a clínica que é a depressão. A depressão pode ser orgânica, pode ser reativa, pode ser endógena, pode ser por estresses sociais. A depressão é uma doença só? São muitas doenças? A depressão reativa é diferente da depressão endógena? Ou essa major depression da classificação é a verdadeira depressão? Não creio. Eu acho que o psicanalista trabalha com pessoas de acordo com uma teoria na qual há uma evolução gradativa de todo o psiquismo, e que as alterações dessa evolução são ora neurose, ora psicose e, ao mesmo tempo podem ser neurose e psicose e podem ser só neurose ou só psicose. De modo que eu, que trabalhei em diagnóstico, e cuja linha principal da minha carreira foi o diagnóstico psiquiátrico, eu que queria chegar às doenças, eu penso que é um objetivo difícil de conseguir, senão do ponto de vista da epidemiologia, da psiquiatria administrativa, das classificações, que dão esses absurdos de se retirar uma coisa que existe realmente, que é a neurose, para se criar um sistema de nomenclatura diferente. $\mathrm{Na}$ realidade, o grande problema da psiquiatria no momento atual é que a psiquiatria deixou de ser uma especialidade de ciência natural ou de ciência psicológica e se tornou uma ciência de sistema. Estabelece-se um sistema de psiquiatria, esse sistema tem dimensões, esse sistema tem sinais: só é ataque de pânico se teve a, b, c, d, nas três últimas semanas, se repetiu seis vezes no ano passado. Isso é um sistema de referência, mas isto não é a psiquiatria que eu aprendi e que procurei ensinar. 
Sobre o resultado de se acompanhar pacientes em tratamento psiquiátricos com análise

Evidentemente que o doente que foi acompanhado psicanaliticamente teve outras oportunidades que o doente que tomou apenas imipramina. Se o doente tomou imipramina e fez uma análise, ele deve melhorar muito mais suas condições de vida posteriormente; quer dizer, a depressão dele, que foi um sintoma que exigiu até eletrochoque, vamos dizer assim, se ele for analisado, melhorará muito mais. Agora, eu nunca pensei em separar lotes de pacientes analisados, pacientes não analisados e verificar o produto.

Conferência pronunciada por José Leme Lopes na Sociedade Brasileira de Psicanálise do Rio de Janeiro em 24 de outubro de 1988. 